\title{
Gambaran kematian perinatal di RSUP Prof. Dr. R. D. Kandou Manado tahun 2015
}

\author{
${ }^{1}$ Wellina R. Simamora \\ ${ }^{2}$ Hermie M. M. Tendean \\ ${ }^{2}$ Linda Mamengko
}

\author{
${ }^{1}$ Kandidat Skripsi Fakultas Kedokteran Universitas Sam Ratulangi Manado \\ ${ }^{2}$ Bagian Obstetri dan Ginekologi Fakultas Kedokteran Universitas Sam Ratulangi Manado \\ Email: simamoraellin@gmail.com
}

\begin{abstract}
Perinatal Mortality rate is an indicator to measure the level of health development level of a country and the quality of life from its society. Perinatal death occurred more than 5 million cases per year. This study aims to determine the enormity of stillbirth number, early neonatal death and causes of perinatal death in RSUP Prof. DR. R. D. Kandou Manado in 2015. The research design used is a retrospective descriptive study with cross sectional approach. The research sample is all mothers do labor and childbirth with perinatal mortality in RSUP Prof. DR. R. D. Kandou Manado in 2015. There are 1,649 live births in 2015 with case deaths perinatal period 85, 23 genesis differences case consists of stillbirth and early neonatal death of genesis 62. Conclusion. The percentage of stillbirth is $27.1 \%$, early neonatal Mortality is $72.9 \%$ with often fence is sepsis in RSUP Prof. DR. R. D. Kandou Manado in 2015.
\end{abstract}

Keywords: perinatal mortality, stillbirth, early neonatal death, perinatal mortality rate.

\begin{abstract}
Abstrak: Angka kematian perinatal merupakan indikator dalam menilai tingkat pembangunan kesehatan dari suatu negara serta kualitas hidup dari masyarakatnya. Kematian perinatal terjadi lebih dari 5 juta kasus per tahun. Tujuan dari penelitian ini untuk mengetahui besarnya angka lahir mati, kematian neonatal dini dan penyebab kematian perinatal di RSUP Prof. DR. R. D. Kandou Manado tahun 2015. Desain penelitian yang digunakan adalah penelitian deskriptif retrospektif dengan pendekatan potong lintang. Sampel penelitian ini adalah seluruh ibu yang melakukan persalinan dan melahirkan dengan kematian perinatal di RSUP Prof. DR. R. D. Kandou Manado tahun 2015. Terdapat 1649 kelahiran hidup pada tahun 2015 dengan jumlah kasus kematian perinatal sebanyak 85 kasus terdiri atas 23 kejadian lahir mati dan 62 kejadian kematian neonatal dini. Simpulan. Persentase kejadian lahir mati sebesar 27,1\%, kematian neonatal dini sebesar 72,9\% dengan penyebab kematian paling sering adalah sepsis di RSUP Prof. DR. R. D. Kandou Manado tahun 2015.
\end{abstract}

Kata kunci: kematian perinatal, lahir mati, kematian neonatal dini, angka kematian perinatal.

Angka kematian perinatal merupakan indikator dalam menilai tingkat pembangunan kesehatan dari suatu negara serta kualitas hidup dari masyarakatnya. ${ }^{1}$ Kematian perinatal adalah kematian janin pada usia kehamilan 28 minggu atau lebih dan kematian bayi pada 7 hari pertama kehidupan. Kematian perinatal terjadi lebih dari 5 juta kasus per tahun. ${ }^{2}$ Secara global kematian bayi tertinggi ada pada periode neonatal yaitu sekitar 3,3 juta bayi. Dalam bulan pertama, seperempat sampai setengah dari semua kematian terjadi dalam 24 jam pertama kehidupan, dan $75 \%$ terjadi pada 
minggu pertama.

Angka kematian tertinggi didapatkan di wilayah Afrika (63 per 1.000 kelahiran hidup), enam kali lebih tinggi daripada di kawasan Eropa (10 per 1.000 kelahiran hidup). Penelitian yang dilakukan di Inggris pada tahun 2013, didapatkan 4.722 kasus kematian perinatal dimana terdapat sebanyak 3.286 kasus lahir mati dan 1.436 kasus kematian neonatal dini. Angka kematian perinatal yang didapat adalah 6 kematian per 1000 kelahiran hidup dimana 4,2 kematian per 1000 kelahiran hidup pada bayi lahir mati dan 1,8 per 1000 kelahiran hidup pada kematian neonatal dini. ${ }^{3}$

Kematian perinatal di beberapa negaranegara berkembang berdasarkan laporan Levels \& Trends in Child Mortality tahun 2012, Bangladesh 24 per 1.000 kelahiran hidup, India 31 per 1.000 kelahiran hidup, Pakistan 42 per 1.000 kelahiran hidup, Myanmar 26 per 1.000 kelahiran hidup. Sedangkan angka kematian neonatal di Indonesia 15 per 1000 kelahiran hidup. ${ }^{4}$

Menurut SDKI tahun 2012 terdapat 118 kasus lahir mati dan 268 kasus kematian neonatal dini yang dilaporkan. Dari hasil survei tersebut ditemukan hasil angka kematian perinatal di Indonesia sebesar 26 kematian per 1000 kelahiran hidup. Terjadi peningkatan angka kematian perinatal dari hasil survei sebelumnya yang dilakukan pada tahun 2007 dan 2002 yaitu masing-masing 25 dan 24 kematian per 1000 kelahiran hidup. ${ }^{5}$

Angka kematian perinatal tertinggi di Indonesia menurut hasil SDKI tahun 2012 yaitu terdapat di provinsi Maluku Utara dengan 37 kematian per 1000 kelahiran hidup, Papua Barat dengan 35 kematian per 1000 kelahiran hidup dan Nusa Tenggara Barat dengan 33 kematian per 1000 kelahiran hidup sedangkan angka kematian perinatal terendah ditemukan di provinsi Kalimantan Timur dengan 12 kematian per 1000 kelahiran hidup. ${ }^{5}$

Berdasarkan SDKI tahun 2012 didapatkan angka kematian perinatal di provinsi Sulawesi Utara dengan 23 kematian per 1000 kelahiran hidup. Angka kematian perinatal provinsi Sulawesi Utara menenmpati urutan ke-15 dari 33 provinsi yang dilakukan survei serupa. ${ }^{5}$

Berdasarkan hal-hal tersebut, peneliti ingin mengetahui dan meneliti lebih lanjut mengenai gambaran kematian perinatal di RSUP Prof. Dr. R. D. Kandou Manado tahun 2015.

\section{METODE PENELITIAN}

Desain penelitian yang digunakan adalah penelitian deskriptif retrospektif dengan pendekatan cross sectional. Penelitian dilakukan pada periode 1 Januari 2015 - 31 Desember 2015 di RSUP Prof. DR. R. D. Kandou Manado. Populasi penelitian ini adalah seluruh ibu yang melahirkan dan melakukan persalinan dengan kematian perinatal di RSUP Prof. DR. R. D. Kandou Manado tahun 2015. Sampel penelitian iniadalah subyek yang diambil dari populasi dan memenuhi kriteria inklusi dan eksklusi penelitian.

Kriteria inklusi ialah seluruh ibu yang melahirkan dan melakukan persalinan di RSUP Prof. DR. R. D. Kanodu Manado tahun 2015. Kriteria eksklusi ialah seluruh ibu yang melahirkan dan melakukan persalinan di luar RSUP Prof. DR. R. D. Kanodu Manado tahun 2015, pasien yang tidak memiliki catatan rekam medik lengkap serta catatan rekam medik pasien yang hilang.

Pengumpulan data dilakukan dengan melihat catatan rekam medik pasien dengan kematian perinatal di bagian Obstetri dan Ginekologi RSUP Prof. DR. R. D. Kandou Manado tahun 2015 kemudian pengolahan data dilakukan secara manual dan menggunakan komputer serta disajikan dalam bentuk penjelasan dan tabel distribusi frekuensi.

\section{HASIL PENELITIAN}

Selama tahun 2015 didapatkan 1649 jumlah kelahiran hidup yang terjadi di RSUP Prof. Dr. R. D. Kandou Manado dan untuk jumlah kasus kematian perinatal terdapat 85 kasus yang terdiri dari 23 kasus lahir mati dan 62 kasus kematian neonatal dini. Hasil penelitian menurut umur ibu, usia kehamilan, paritas, berat bayi lahir, 
penyakit selama kehamilan, penyebab kematian dan jenis persalinan.

Berdasarkan Tabel 1 dapat dilihat bahwa kasus kematian perinatal paling banyak terjadi pada ibu dengan umur 20-34 tahun dengan persentase sebesar $63,5 \%$.

Tabel 1. Distribusi Kematian Perinatal Menurut Umur Ibu

\begin{tabular}{lllllll}
\hline $\begin{array}{l}\text { Kelompok } \\
\text { umur } \\
\text { (tahun) }\end{array}$ & $\begin{array}{l}\text { Lahir } \\
\text { Mati }\end{array}$ & \multicolumn{4}{c}{$\begin{array}{l}\text { Kematian } \\
\text { Neonatal } \\
\text { Dini }\end{array}$} & $\begin{array}{l}\text { Kematian } \\
\text { Perinatal }\end{array}$ \\
\cline { 2 - 7 } & $\mathrm{n}$ & $\%$ & $\mathrm{n}$ & $\%$ & $\mathrm{n}$ & $\%$ \\
\hline$<20$ & 5 & 5,9 & 8 & 9,4 & 13 & 15,3 \\
$20-34$ & 13 & 15,3 & 41 & 48,2 & 54 & 63,5 \\
$\geq 35$ & 5 & 5,9 & 13 & 15,3 & 18 & 21,2 \\
Total & 23 & 27,1 & 62 & 72,9 & 85 & 100 \\
\hline
\end{tabular}

Berdasarkan Tabel 2 kasus kematian perinatal paling banyak terjadi pada usia kehamilan 28-36 minggu yaitu sebanyak 44 kasus dengan persentase sebesar $51,7 \%$.

Tabel 2. Distribusi Kematian Perinatal Menurut Usia Kehamilan

\begin{tabular}{lllllll}
\hline $\begin{array}{l}\text { Usia } \\
\text { kehamilan } \\
\text { (minggu) }\end{array}$ & $\begin{array}{l}\text { Lahir } \\
\text { Mati }\end{array}$ & $\begin{array}{l}\text { Kematian } \\
\text { Neonatal } \\
\text { Dini }\end{array}$ & $\begin{array}{l}\text { Kematian } \\
\text { Perinatal }\end{array}$ \\
\cline { 2 - 7 } & $\mathrm{n}$ & $\%$ & $\mathrm{n}$ & $\%$ & $\mathrm{n}$ & $\%$ \\
\hline $28-36$ & 19 & 22,3 & 25 & 29,4 & 44 & 51,7 \\
$37-41$ & 2 & 2,4 & 36 & 42,3 & 38 & 44,7 \\
$\geq 42$ & 2 & 2,4 & 1 & 1,2 & 3 & 3,6 \\
Total & 23 & 27,1 & 62 & 72,9 & 85 & 100 \\
\hline
\end{tabular}

Tabel 3. Distribusi Kematian Perinatal Menurut Paritas Ibu

\begin{tabular}{|c|c|c|c|c|c|c|}
\hline \multirow[t]{2}{*}{ Paritas } & \multicolumn{2}{|c|}{ Lahir Mati } & \multicolumn{2}{|c|}{$\begin{array}{l}\text { Kematian } \\
\text { Neonatal } \\
\text { Dini } \\
\end{array}$} & \multicolumn{2}{|c|}{$\begin{array}{l}\text { Kematian } \\
\text { Perinatal }\end{array}$} \\
\hline & $\mathrm{n}$ & $\%$ & $n$ & $\%$ & $\mathrm{n}$ & $\%$ \\
\hline 0 & 11 & 12,9 & 19 & 22,4 & 30 & 35,3 \\
\hline 1 & 5 & 5,9 & 16 & 18,8 & 21 & 24,7 \\
\hline $2-4$ & 7 & 8,3 & 24 & 28,2 & 31 & 36,5 \\
\hline$\geq 5$ & 0 & 0 & 3 & 3,5 & 3 & 3,5 \\
\hline Total & 23 & 27,1 & 62 & 72,9 & 85 & 100 \\
\hline
\end{tabular}

Berdasarkan tabel 3 dapat dilihat bahwa kasus kematian perinatal paling banyak terjadi pada ibu dengan paritas 2-4 yaitu sebanyak 31 kasus dengan persentase sebesar 36,5\%.

Berdasarkan Tabel di atas, kasus kematian perinatal paling banyak terjadi pada bayi dengan berat lahir 1500-2499 gram yaitu sebanyak 35 kasus dengan persentase sebesar $41,2 \%$.

Tabel 4. Distribusi Kematian Perinatal Menurut Berat Bayi Lahir

\begin{tabular}{lllllll}
\hline $\begin{array}{l}\text { Berat Bayi } \\
\text { Lahir (gram) }\end{array}$ & $\begin{array}{l}\text { Lahir } \\
\text { Mati }\end{array}$ & \multicolumn{3}{c}{$\begin{array}{l}\text { Kematian } \\
\text { Neonatal } \\
\text { Dini }\end{array}$} & $\begin{array}{l}\text { Kematian } \\
\text { Perinatal }\end{array}$ \\
\cline { 2 - 7 } & $\mathrm{n}$ & $\%$ & $\mathrm{~N}$ & $\%$ & $\mathrm{n}$ & $\%$ \\
\hline$<1500$ & 15 & 17,6 & 4 & 4,7 & 19 & 22,3 \\
$1500-2499$ & 5 & 5,9 & 30 & 35,3 & 35 & 41,2 \\
$2500-2999$ & 2 & 2,4 & 12 & 14,1 & 14 & 16,5 \\
$3000-3499$ & 1 & 1,2 & 7 & 8,2 & 8 & 9,4 \\
$3500-3999$ & 0 & 0 & 4 & 4,7 & 4 & 4,7 \\
$\geq 4000$ & 0 & 0 & 5 & 5,9 & 5 & 5,9 \\
Total & 23 & 27,1 & 62 & 72,9 & 85 & 100 \\
\hline
\end{tabular}

Berdasarkan Tabel 5 dapat dilihat bahwa kasus kematian perinatal paling banyak terjadi pada ibu yang menderita penyakit PER, hipertensi dan ISK yang masing-masing berjumlah 4 kasus dengan persentase sebesar $4,7 \%$.

Tabel 5. Distribusi Kematian Perinatal Menurut Penyakit Ibu

\begin{tabular}{|c|c|c|c|c|c|c|}
\hline \multirow[t]{2}{*}{$\begin{array}{l}\text { Penyakit } \\
\text { Ibu }\end{array}$} & \multicolumn{2}{|c|}{$\begin{array}{l}\text { Lahir } \\
\text { Mati }\end{array}$} & \multicolumn{2}{|c|}{$\begin{array}{l}\text { Kematian } \\
\text { Neonatal } \\
\text { Dini }\end{array}$} & \multicolumn{2}{|c|}{$\begin{array}{l}\text { Kematian } \\
\text { Perinatal }\end{array}$} \\
\hline & $\mathrm{n}$ & $\%$ & $\mathrm{n}$ & $\%$ & $\mathrm{n}$ & $\%$ \\
\hline PER & 4 & 4,7 & & 0 & 4 & 4,7 \\
\hline PEB & 0 & c & & 1,2 & & 1,2 \\
\hline $\begin{array}{l}\text { Impending } \\
\text { eclampsia }\end{array}$ & 0 & 0 & 2 & 2,4 & 2 & 4 \\
\hline Eklar & 1 & 1,2 & 0 & o & & 1,2 \\
\hline Hiper & 0 & 0 & 4 & 4,7 & & 4,7 \\
\hline M & 0 & 0 & 1 & 1,2 & & 1,2 \\
\hline ISK & 0 & 0 & 4 & 4,7 & 4 & 4,7 \\
\hline Asm & 0 & 0 & 1 & 1,2 & & 1,2 \\
\hline & 0 & 0 & 1 & 1,2 & & 1,2 \\
\hline Cacar & 0 & 0 & 1 & 1,2 & 1 & 1,2 \\
\hline Tanpa & 18 & 21,2 & 47 & 55,1 & 65 & 76 \\
\hline Total & 23 & 27,1 & 62 & 72,9 & 85 & 100 \\
\hline
\end{tabular}

Berdasarkan Tabel 6 kasus kematian perinatal menurut penyebab kematian 
Simamora, Tendean, Mamengko: Gambaran kematian perinatal...

paling banyak terjadi pada sepsis yaitu sebanyak 40 kasus dengan persentase sebesar $47 \%$.

Tabel 6. Distribusi Kematian Perinatal Menurut Penyebab Kematian

\begin{tabular}{lllllll}
\hline $\begin{array}{l}\text { Penyebab } \\
\text { Kematian }\end{array}$ & \multicolumn{2}{l}{$\begin{array}{l}\text { Lahir } \\
\text { Mati }\end{array}$} & \multicolumn{3}{c}{$\begin{array}{l}\text { Kematian } \\
\text { Neonatal } \\
\text { Dini }\end{array}$} & \multicolumn{2}{l}{$\begin{array}{l}\text { Kematian } \\
\text { Perinatal }\end{array}$} \\
\cline { 2 - 7 } & $\mathrm{n}$ & $\%$ & $\mathrm{n}$ & $\%$ & $\mathrm{n}$ & $\%$ \\
\hline Prematuritas & 13 & 15,3 & 0 & 0 & 13 & 15,3 \\
KPD & 2 & 2,4 & 0 & 0 & 2 & 2,4 \\
IUFD & 8 & 9,4 & 0 & 0 & 8 & 9,4 \\
Gagal & 0 & 0 & 14 & 16,4 & 14 & 16,4 \\
Napas & & & & & & \\
Sepsis & 0 & 0 & 40 & 47 & 40 & 47 \\
$\begin{array}{l}\text { Multi Organ } \\
\text { Failure }\end{array}$ & 0 & 0 & 6 & 7,1 & 6 & 7,1 \\
$\begin{array}{l}\text { Vitamin K } \\
\text { Deficiency }\end{array}$ & 0 & 0 & 1 & 1,2 & 1 & 1,2 \\
$\begin{array}{l}\text { Bleeding } \\
\text { Inborn }\end{array}$ & 0 & 0 & 1 & 1,2 & 1 & 1,2 \\
$\begin{array}{l}\text { Errors of } \\
\text { Metabolism }\end{array}$ & & & & & & \\
Total & 23 & 27,1 & 62 & 72,9 & 85 & 100 \\
\hline
\end{tabular}

Berdasarkan 7 dapat dilihat bahwa kasus kematian perinatal paling banyak terjadi pada jenis persalinan secara spontan yaitu sebanyak 63 kasus dengan persentase sebesar $74,1 \%$.

Tabel 7. Distribusi Kematian Perinatal Menurut Jenis Persalinan

\begin{tabular}{lllllll}
\hline $\begin{array}{l}\text { Jenis } \\
\text { Persalinan }\end{array}$ & $\begin{array}{l}\text { Lahir } \\
\text { Mati }\end{array}$ & $\begin{array}{l}\text { Kematian } \\
\text { Neonatal } \\
\text { Dini }\end{array}$ & $\begin{array}{l}\text { Kematian } \\
\text { Perinatal }\end{array}$ \\
\cline { 2 - 7 } & $\mathrm{n}$ & $\%$ & $\mathrm{n}$ & $\%$ & $\mathrm{n}$ & $\%$ \\
\hline Spontan & 21 & 24,7 & 42 & 49,4 & 63 & 74,1 \\
SC & 2 & 2,4 & 19 & 22,3 & 21 & 24,7 \\
EV & 0 & 0 & 1 & 1,2 & 1 & 1,2 \\
Total & 23 & 27,1 & 62 & 72,9 & 85 & 100 \\
\hline
\end{tabular}

Berdasarkan Tabel 8 didapatkan bahwa angka kematian perinatal yang terjadi di RSUP Prof. Dr. R. D. Kandou Manado pada tahun 2015 adalah 51,5 per 1000 kelahiran hidup.

Tabel 8. Distribusi Angka Kematian Perinatal Tahun 2015

\begin{tabular}{llllll}
\hline Tahun & $\begin{array}{l}\text { Lahir } \\
\text { hidup }\end{array}$ & $\begin{array}{l}\text { Lahir } \\
\text { mati }\end{array}$ & KND & $\begin{array}{l}\text { Kematian } \\
\text { Perinatal }\end{array}$ & AKP \\
\hline 2015 & 1649 & 23 & 62 & 85 & 51,5 \\
\hline
\end{tabular}

\section{BAHASAN}

Dari hasil penelitian yang dilakukan di RSUP Prof. Dr. R. D. Kandou Manado selama bulan Sepetember hingga November 2016 didapatkan sebanyak 85 kasus kematian perinatal yang terjadi pada tahun 2015. Terdiri atas 23 kasus lahir mati dan 62 kasus kematian neonatal dini.

Distribusi frekuensi yang tergambar dalam tabel 4.1 berdasarkan umur ibu didapatkan sebanyak 54 kasus kematian perinatal terjadi pada ibu dengan umur 20 34 tahun dengan persentase sebesar $63,5 \%$. Angka tersebut terdiri atas 13 kasus lahir mati $(15,3 \%)$ dan 31 kasus kematian neonatal dini $(48,2 \%)$. Sementara itu, kasus kematian perinatal yang paling rendah terjadi pada ibu dengan kelompok umur $<20$ tahun yaitu sebanyak 13 kasus dengan persentase sebesar $15,3 \%$ yang terdiri atas 5 kasus lahir mati $(5,9 \%)$ dan 8 kasus kematian neonatal dini $(9,4 \%)$.

Hasil penelitian tersebut didukung oleh penelitian yang dilakukan oleh Marie Blomberg dkk tahun 2014 yaitu pada kelompok usia ibu $<20$ tahun tidak menunjukkan peningkatan resiko terjadinya kematian perinatal akan tetapi menunjukkan peningkatan kejadian prematuritas < 32 minggu. Sementara pada kelompok usia ibu $\geq 30$ tahun menunjukkan peningkatan resiko yang signifikan terhadap kejadian kematian perinatal. $^{6}$

Dalam Tabel 4.2 didapatkan data mengenai kasus kematian perinatal berdasarkan usia kehamilan paling banyak terjadi pada ibu dengan usia kehamilan 2836 minggu yaitu sebanyak 44 kasus kematian perinatal dengan persentase sebesar 51,7\% yang terdiri atas 19 kasus lahir mati $(22,4 \%)$ dan 25 kasus kematian neonatal dini $(29,3 \%)$. Frekuensi terendah didapatkan pada kelompok ibu dengan usia kehamilan $\geq 42$ minggu yaitu sebanyak 3 kasus kematian perinatal dengan persentase sebesar 3,6\% terdiri atas 1 kasus lahir mati 
$(1,2 \%)$ dan 2 kasus kematian neonatal dini $(2,4 \%)$.

Penelitian yang dilakukan oleh Joy. E Lawn dkk tahun 2010 yang menyatakan bahwa kematian perinatal paling tinggi terjadi pada kelompok dengan usia kehamilan<32 minggu baik pada negara dengan penghasilan rendah, penghasilan menengah maupun berpenghasilan tinggi. ${ }^{7}$ Hal ini sejalan dengan penelitian yang dilakukan oleh Tomashek dkk tahun 2007 yang menyatakan bahwa usia kehamilan 34 - 36 minggu memiliki angka mortalitas yang lebih tinggi dibandingkan dengan usia kehamilan aterm yaitu sebesar 7,99,5/1000 kelahiran hidup. ${ }^{8}$

Berdasarkan paritas ibu pada tabel 4.3 didapatkan data kasus kematian perinatal paling banyak terjadi pada ibu dengan paritas $2-4$ dengan jumlah sebanyak 31 kasus dengan persentase sebesar 36,5\% yang terdiri atas 7 kasus lahir mati $(8,3 \%)$ dan 24 kasus kematian neonatal dini $(28,2 \%)$. Sementara itu hanya 3 kasus kematian perinatal saja yang terjadi pada kelompok ibu dengan paritas $\geq 5$ dengan persentase sebesar 3,6\% yang didapati pada 3 kasus kematian neonatal dini.

Menurut Eralp Baser dkk tahun 2013 menyatakan bahwa kelompok multipara memiliki kecendurungan secara signifikan untuk mengalami preeklampisa dan kematian janin. Hal ini selaras dengan penelitian diatas yang menunjukkan bahwa kejadian kematian perinatal memang lebih banyak terjadi pada kelompok ibu dengan multipara. ${ }^{9}$

Kasus kematian perinatal terbanyak berdasarkan berat bayi lahir yang tergambar dalam tabel 4.4 terjadi pada kelompok bayi dengan berat bayi lahir 1500 - 2499 gram yaiu sebanyak 35 kasus dengan persentase sebesar $41,2 \%$ yang terdiri atas 5 kasus lahir mati $(5,9 \%)$ dan 30 kasus kematian neonatal dini $(35,3 \%)$. Kasus kematian perinatal paling rendah terjadi pada kelompok bayi dengan berat bayi lahir 3500 - 3999 gram yaitu sebanyak 4 kasus dengan persentase sebesar $4,7 \%$ yang terjadi pada 4 kasus kematian neonatal dini.
Menurut Efriza tahun 2007, BBLR meningkatkan resiko terjadinya asfiksia 2,86 kali lebih besar daripada bayi dengan berat bayi lahir normal. Bayi yang lahir dengan berat bayi lahir rendah sangat peka terhadap perubahan suhu lingkungan, kekurangan oksigen dan infeksi. Dengan kata lain, hal ini meningkatkan resiko terjadinya kejadian kematian perinatal. Hal ini tergambar pada hasil penelitian diatas dimana kejadian kematian perinatal paling banyak terjadi pada kelompok dengan berat bayi lahir $1500-2499$ gram. $^{10}$

Kematian perinatal yang dikaitkan dengan penyakit ibu seperti tergambar dalam tabel 4.5 paling banyak terjadi pada ibu yang menderita penyakit hipertensi, ISK dan PER selama kehamilannya yaitu masing-masing sebanyak 4 kasus dengan persentase $4,7 \%$. Sementara itu penyakit PEB, eklampsia, DM, asma, epilepsi dan cacar air menempati urutan terendah sebanyak 1 kasus dengan persentase 1,2\%.

Hasil penelitian tersebut sesuai dengan hasil penelitian yang didapatkan oleh Manisha Behal tahun 2015 yang menyatakan bahwa kejadian kematian perinatal paling banyak terjadi pada kelompok ibu dengan preeklampsia, eklampsia dan persalinan macet. ${ }^{11}$

Pada Tabel 4.6 berdasarkan penyebab kematian bayi, kasus kematian perinatal paling banyak terjadi disebabkan oleh sepsis yaitu sebanyak 40 kasus dengan persentase sebesar $47 \%$ yang terjadi pada kasus kematian neonatal dini. Pada kasus lahir mati didapatkan sebanyak 13 kasus lahir mati yang disebabkan oleh karena prematuritas dengan persentase sebesar $15,3 \%$.

Sepsis merupakan penyebab kematian perinatal paling banyak pada penelitian ini. Hasil ini juga didukung oleh penelitian Schrag SJ dkk tahun 2012 yang menyatakan bahwa dari 8129 bayi, 289 diantaranya mengalami early osnet sepsis, 34 mengalami late onset sepsis, $49 \mathrm{di}$ diagnosis mengalami sepsis neonatal yang dikonfirmasi dengan pemeriksaan kultur dan 71 bayi meninggal pada periode perinatal. $^{12}$ 
Berdasarkan tabel 4.7 menurut jenis persalinan, kasus kematian perinatal paling banyak terjadi pada jenis persalinan spontan yaitu sebanyak 63 kasus dengan persentase sebesar $74,1 \%$ yang terdiri atas 20 kasus lahir mati $(23,5 \%)$ dan 43 kasus kematian neonatal dini $(50,6 \%)$.

Berdasarkan penelitian yang dilakukan Manisha Behal tahun 2015 didapatkan hasil bahwa kematian perinatal paling banyak terjadi pada kelompok yang melakukan persalinan pervaginam yaitu sebanyak 47 kejadian kematian perinatal. Hal ini sesuai dengan penelitian di atas yang menunjukkan bahwa kejadian kematian perinatal paling banyak terjadi pada kelompok yang melakukan persalinan pervaginam. ${ }^{11}$

\section{SIMPULAN}

Berdasarkan hasil penelitian di atas, dapat ditarik kesimpulan yaitu terdapat 85 kasus kematian perinatal yang terjadi di RSUP Prof. Dr. R. D. Kandou Manado tahun 2015 terbagi atas 23 kejadian lahir mati $(27,1 \%)$ dan 62 kejadian kematian neonatal dini $(72,9 \%)$ dengan penyebab yang paling sering terjadi adalah sepsis.

\section{SARAN}

Bagi masyarakat diharapkan dapat menambah pemahaman dan pengetahuan tentang berbagai macam faktor resiko dan penyebab kematian perinatal sehingga dapat meningkatkan kesadaran pada masyarakat khususnya pada ibu hamil untuk rutin memeriksakan kesehatan dan kehamilannya ke fasilitas ataupun tenaga kesehatan setempat seperti puskesmas ataupun bidan. Bagi penelitian selanjutnya diharapkan dapat melanjutkan penelitian ini dengan menambah variable-variabel lain yang berhubungan dengan kematian perinatal, serta pengembangan penelitian untuk menggali data- data lebih mendalam yang mempengaruhi kematian perinatal.

\section{DAFTAR PUSTAKA}

1. Departemen Kesehatan RI. Riset kesehatan dasar 2007. Jakarta: Kemenkes RI, 2008 .
2. MacDorman MF, Gregory ECW. Fetal and perinatal mortality : United States, 2013. Centers for disease control and prevention (CDC). 2015;64(8):1-11.

3. Allanson ER, Gardosi J, Pattinson RC, Francis A, Vogel JP, Erwich JJHM, et al. The WHO application of ICD-10 to deaths during the perinatal period (ICM-PM): results from pilot database testing in South Africa and United Kingdom. R Coll J Obstet Gynecol. 2016;123(10):1-10

4. Manktelow BN, Smith LK, Evans TA, Hyman-Taylor P, Kurinczuk JJ, Field DJ, et al. Perinatal mortality surveillance report UK perinatal deaths for births from January to December 2013. MBRRACE-UK. 2015

5. Badan Pusat Statistik. 2013. Survei Demografi dan Kesehatan Indonesia (SDKI) 2012. Jakarta: Badan Pusat Statistik.

6. Blomberg M, Tyrberg RB, Kjølhede P. Impact of maternal age on obstetric and neonatal outcome with emphasis on primiparous adolescents and older women: a Swedish Medical Birth Register Study. BMJ.2014.

7. Lawn JE, Gravett MG, Nunes TM, Rubens CE, Stanton C. Global report on preterm birth and stillbirth (1 of 7): definitions, description of the burden and opportunities to improve data. BMC Pregnancy and Childbirth. 2010;110(10).

8. Tomashek KM, Shapiro-Mendoza CK, Davidoff MJ, Petrini JR. Differences in mortality between latepreterm and term singleton infants in the United States, 1995-2002. J Pediatr. 2007;151(5): 450-456.

9. Eralp B, Doğa SK, Selçuk E, Fatih KM, Mahmut YI, et al. The impact of parity on perinatal outcomes in pregnancies complicated by advanced maternal age. J Turk Ger Gynecol Assoc. 2013;14(4):205-209.

10. Efriza. Determinan kematian neonatal dini di RSUD Dr. Achmad Mochtar Bukittinggi. Desember 2007; 2(3):99105.

11. Behal Manisha, Vinayak Rajeev. Maternal risk factors for perinatal 
mortality. Indian Journal of Obstetrics and Gynecology Research. April-June 2015;2(2):92-96.

12. Chrag SJ, Cutland CL, Zell ER, Kuwanda L, Buchmann EJ, et al. Risk factors for neonatal sepsis and perinatal death among infants enrolled in the prevention of perinatal sepsis trial, Soweto, South Africa. Pediatr Infect Dis J. Agustus 2012;31(8):821-6. 